\title{
Effect of the Deprivation of Amino Acids on Conidia of Neurospora crassa
}

\author{
By GUADALUPE" ESPIN AND JAIME MORA \\ Departamento de Biología Molecular, Instituto de Investigaciones Biomédicas, \\ Universidad Nacional Autónoma de México, México 20, D.F.
}

(Received 23 May 1977; revised 29 July 1977)

\begin{abstract}
Arginine and glutamine, which prevents the catabolism of arginine, are accumulated when conidia of auxotrophic mutants of Neurospora crassa are deprived of an amino acid. This accumulation requires sources of carbon and nitrogen, an intact arginine biosynthetic pathway, de novo synthesis of pyrimidines and protein synthesis. There is coordination between the synthesis of glutamine and the synthesis and catabolism of arginine. Conditions which allow these amino acids to accumulate prevent exogenous arginine from being catabolized.

Since more than half of the accumulated amino nitrogen is stored as glutamine and arginine, it is proposed that these amino acids are nitrogen and/or carbon reservoirs under non-growth conditions.
\end{abstract}

\section{INTRODUCTION}

The auxotrophic strain prol-3 of Neurospora crassa grows on proline (Vogel \& Bonner, 1954), as well as on arginine and ornithine, through the action of a general amino acid permease (Pall, 1969, I970; Sánchez, Martínez \& Mora, 1972), an arginase (Castañeda, Martuscelli \& Mora, 1967; Davis, Lawless \& Port, 1970) and an ornithine- $\delta$-transaminase (Davis \& Mora, I968). These enzymes lead to the formation of glutamic acid and glutamic acid $\gamma$-semialdehyde, a proline precursor which strain prol-3 is unable to synthesize by the normal biosynthetic pathway (Vogel \& Bonner, 1954).

Paradoxically strain prol-3 does not use endogenously synthesized ornithine and arginine as proline precursors, and when incubated in minimal medium it accumulates arginine. In this paper we report the accumulation of glutamine and arginine in conidia of Neurospora crassa when they are deprived of an amino acid. The results presented here bear some similarity to the accumulation of amino acids that has been reported to occur in mycelium of Neurospora crassa (Carsiotis \& Jones, 1974; Carsiotis, Jones \& Wesseling, 1974) and in Saccharomyces cerevisiae (Schurch, Miozzari \& Hutter, 1974).

\section{METHODS}

Organisms. Stocks came from the collection of J. Mora or from the Fungal Genetics Stock Center at Humboldt State University Foundation, Arcata, California, U.S.A. The basic strains were: the proline auxotrophs prol- 1 , prol-3 and prol-4; the arginine auxotrophs arg- 5 and arg-6; the tryptophan auxotrophs tryp-I, tryp-2, tryp-3 and tryp-4; the histidine auxotrophs his-3 and his-6; the lysine auxotroph lys-2; the phenylalanine auxotroph phe-I; the tyrosine auxotroph tyr-I; the aromatic amino acids auxotroph arom-I; the isoleucine-valine auxotroph $i v-r$; the valine auxotroph val (FGSC566); and the uridine auxotroph pyr-3a. All double mutants were obtained from appropriate crosses of these stocks.

Growth conditions. Neurospora crassa was routinely grown in minimal medium N (MM) of Vogel (I964) 
supplemented with $1 \cdot 5 \%(\mathrm{w} / \mathrm{v})$ sucrose. In certain experiments, MM was used alone or $2 \%(\mathrm{v} / \mathrm{v}) \mathrm{glycerol}$ was substituted for sucrose and $\mathrm{NH}_{4} \mathrm{NO}_{3}$ was replaced by other nitrogen sources. Crosses were made on $\mathrm{I} \cdot 7 \%(\mathrm{w} / \mathrm{v})$ corn meal agar (Difco) in the dark at $25^{\circ} \mathrm{C}$. Plating for ascospores was done on MM supplemented with $0.05 \%(w / v)$ glucose, $0.05 \%(w / v)$ fructose, $1 \%(w / v)$ sorbose and solidified with $2 \%(w / v)$ agar.

Conidia were harvested from slants of MM supplemented with $1 \cdot 5 \%(w / v)$ sucrose which were incubated for 3 days in the dark at $29^{\circ} \mathrm{C}$ followed by 2 days in the light at $25^{\circ} \mathrm{C}$. Growth in liquid medium was carried out in $250 \mathrm{ml}$ Florence flasks containing $200 \mathrm{ml} \mathrm{MM}$ inoculated with filtered conidia and aerated with humidified air at $25^{\circ} \mathrm{C}$. In experiments which involved a transfer from one medium to another, conidia were filtered and washed using Millipore filters (type RAWP 047) and resuspended.

Preparation of soluble extracts for amino acid analysis. Conidia were harvested on Millipore filters and washed with distilled water. Glutamic acid and glutamine were extracted by homogenizing the cells in $20 \mathrm{ml}$ $80 \%(\mathrm{v} / \mathrm{v})$ ethanol containing $0.5 \mu \mathrm{Ci}$ of $\mathrm{L}-\left[\mathrm{U}-{ }^{14} \mathrm{C}\right]$ glutamine. The homogenates were boiled for $10 \mathrm{~min}$, cooled and membrane filtered. The alcohol-insoluble material was re-extracted in $20 \mathrm{ml} 80 \%$ (v/v) ethanol. The filtrates containing the free amino acids were lyophilized and the dried samples were resuspended in $2 \mathrm{ml}$ deionized water plus $0 . \mathrm{I} \mu \mathrm{Ci}$ of $\mathrm{L}-\left[\mathrm{U}-{ }^{14} \mathrm{C}\right]$ glutamic acid. Glutamic acid and glutamine were separated and measured using the method of Yemm \& Cocking (1955) as modified by Ferguson \& Sims (1974). Glutamic acid and glutamine concentrations were calculated from the dilution of the specific radioactivity of the labelled compounds.

Arginine was extracted from filtered conidia with $2 \mathrm{ml} 5 \%(\mathrm{w} / \mathrm{v})$ trichloroacetic acid. After centrifugation the arginine was measured in the supernatant fluid by the method of Van Pilsum et al. (I956).

Samples for amino acid analysis were prepared by extracting conidia with $I \%(w / v)$ picric acid. After centrifugation, the supernatant was passed through a column (15 $\times 40 \mathrm{~mm}$ ) of Dowex resin AGI X-2 (200 to $400 \mathrm{mesh}$, chloride form). Amino acids were eluted with $7 \mathrm{ml} 0.02 \mathrm{M}-\mathrm{HCl}$, followed by $2 \mathrm{ml}$ water. The amino acid analyses were carried out on the neutralized eluates using a Technicon amino acid analyser. Ornithine was separated from the other amino acids as previously described (Mora, Salceda \& Sánchez, 1972) and measured by the method of Chinard (1952).

Growth determination. Conidia were collected on membrane filters (Millipore, type HA, pore size $0.45 \mu \mathrm{m}$ ), washed with 2 vols distilled water and placed in $2 \mathrm{ml} 5 \%(\mathrm{w} / \mathrm{v})$ trichloroacetic acid. After centrifugation, the precipitate was resuspended in I M-NaOH. Protein was determined by the method of Lowry et al. (195I) using bovine serum albumin as standard.

Chemicals. All amino acids, indole and bovine serum albumin were obtained from Sigma. Uridine and cycloheximide were purchased from Calbiochem. Ninhydrin was obtained from Pierce Chemical Co., Rockford, Illinois, U.S.A.

\section{RESULTS}

\section{Glutamine and arginine accumulation during amino acid deprivation}

The conidia of the proline auxotroph prol-3 accumulated arginine intracellularly when they were incubated in MM (Fig. I). The accumulation of arginine started immediately, and after $24 \mathrm{~h}$ reached a concentration at least 20 -fold higher than that in the inoculum. This accumulation was the consequence of a biosynthetic process, since in the single auxotrophs arg-5 and arg-6 and in the double auxotrophs arg-5 prol-3 and arg-6 prol-3, no accumulation occurred when incubated in MM (Fig. r). Other amino acid auxotrophs incubated in MM also accumulated arginine (Table I) but no accumulation was observed when the arg- 5 mutation was present in addition to one of these auxotrophs. Arginine did not accumulate when the amino acid auxotrophs were grown in $\mathrm{MM}$ plus the required amino acid, and accumulation was less than in $\mathrm{MM}$ when they were incubated in MM in the presence of cycloheximide (Table 2). Ornithine, an arginine precursor, was not accumulated when conidia of prol-3 and tryp-2 were incubated in MM. The deprivation of uridine in the auxotrophic strain pyr-3a did not induce the accumulation of arginine when conidia were incubated in MM.

When glycerol was substituted for sucrose, there was a threefold decrease in arginine accumulation in strain prol-3; when the carbon source was omitted, no accumulation was found (Fig. 2). If the ammonium nitrogen of the medium was replaced by another nitrogen source such as glutamine, then in the presence of glycerol accumulation also decreased (Fig. 2). In the absence of a nitrogen supply the prol-I, prol-3, prol-4, his-3 and his-6 


\section{Table I. Effect of amino acid deprivation on the accumulation of arginine}

MM was inoculated with conidia of different amino acid auxotrophs which were thus deprived of the corresponding amino acid. Arginine concentration was measured immediately $(\mathrm{o} \mathrm{h})$ and after $24 \mathrm{~h}$ incubation. Results are expressed as $\mu \mathrm{mol}$ arginine (mg protein) ${ }^{-1}$.

\begin{tabular}{|c|c|c|c|c|c|}
\hline \multirow[b]{2}{*}{ Strain } & \multicolumn{2}{|c|}{$\begin{array}{l}\text { Arginine concn after } \\
\text { incubation for: }\end{array}$} & \multirow[b]{2}{*}{ Strain* } & \multicolumn{2}{|c|}{$\begin{array}{l}\text { Arginine concn after } \\
\text { incubation for: }\end{array}$} \\
\hline & oh & $24 \mathrm{~h}$ & & oh & $24 \mathrm{~h}$ \\
\hline $\operatorname{tryp}-I$ & 0.03 & $0.8 I$ & prol-4 & 0.02 & 0.30 \\
\hline tryp-2 & 0.07 & 0.95 & phe-I & 0.08 & $0.72 \dagger$ \\
\hline tryp-3 & 0.04 & 0.40 & tyr-I & 0.03 & $0.36 t$ \\
\hline tryp -4 & 0.04 & 0.76 & arom-I (phe) & 0.05 & 0.37 \\
\hline his-3 & 0.10 & $2 \cdot 10$ & arom-I (tryp) & 0.05 & 0.53 \\
\hline his-6 & 0.04 & $\mathbf{I} \cdot 70$ & $i v-I$ (ile) & 0.12 & $0.4 I$ \\
\hline$l y s-2$ & 0.03 & 0.92 & $i v-I$ (val) & 0.12 & $0.35 \dagger$ \\
\hline prol-I & 0.02 & 0.42 & val & 0.03 & 0.19 \\
\hline prol-3 & 0.03 & 0.72 & & & \\
\hline
\end{tabular}

* The abbreviations in parentheses indicate the amino acid of which the mutant was deprived. $\dagger$ Arginine was measured after $10 \mathrm{~h}$ since growth was observed at longer incubation times.

\section{Table 2. Effect of cycloheximide and amino acid supplementation on the accumulation of arginine}

Conidia were introduced into $250 \mathrm{ml}$ flasks and incubated for $24 \mathrm{~h}$ in $\mathrm{MM}$ with and without cycloheximide (10 $\mu \mathrm{g} \mathrm{ml}^{-1}$ ) or for $12 \mathrm{~h}$ in MM plus the amino acid required (100 $\mu \mathrm{g} \mathrm{ml}^{-1}$ ). Results are expressed as $\mu \mathrm{mol}$ arginine (mg protein) ${ }^{-1}$.

\begin{tabular}{lccc} 
Strain & \multicolumn{2}{c}{ Arginine concn after incubation in: } \\
\cline { 2 - 3 } tryp-2 & 0.71 & 0.08 & $\begin{array}{c}\text { MM+ } \\
\text { amino acid } \\
\text { cycloheximide }\end{array}$ \\
his-6 & 1.70 & 0.05 & 0.16 \\
lys-2 & 0.59 & 0.02 & 0.18 \\
prol-3 & 0.72 & 0.10 & 0.23 \\
am & & 0.22
\end{tabular}

auxotrophs did not accumulate arginine, although others, such as the lys-2 and tryp-2 auxotrophs, accumulated arginine at a reduced rate even in absence of a nitrogen source.

An amino acid analysis of the acid-soluble extract of conidia of strain prol-3 incubated for $\mathrm{Io} h$ in $\mathrm{MM}$ is shown in Table 3. It can be calculated from these results that after deprivation there was a $2 \cdot 6$-fold increase in the amino nitrogen, of which $32.6 \%$ was in arginine and $21.9 \%$ was in glutamine. In contrast, $18.1 \%$ of the amino nitrogen in the inoculum was in arginine and $14.5 \%$ was in glutamine. An appreciable cysteine pool was formed and glutamate was one of the major pool amino acids at both sampling times. Similar results were obtained for strain tryp-2 after deprivation.

\section{Catabolism of arginine during amino acid deprivation}

Since the prol-3 mutant did not grow in conditions where arginine accumulated we assumed that this amino acid was not catabolized during proline deprivation (Fig. 3). Conidia of the prol-3 mutant grew in arginine only when it was present in the medium at inoculation (zero time). The addition of arginine 3,6 or $9 \mathrm{~h}$ after inoculation into MM did not promote growth in this mutant when it had been deprived of proline for $3 \mathrm{~h}$. The addition of ornithine to MM $6 \mathrm{~h}$ after inoculation did initiate growth. Similar results were obtained with conidia of strain prol-4, which also grows in proline, arginine or ornithine. The lack of growth in the presence of arginine after incubation in MM was not related to a low level of intracellular arginine. 


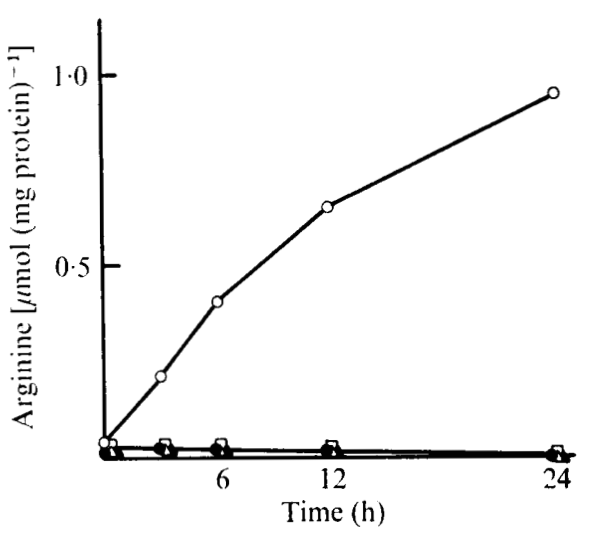

Fig. I

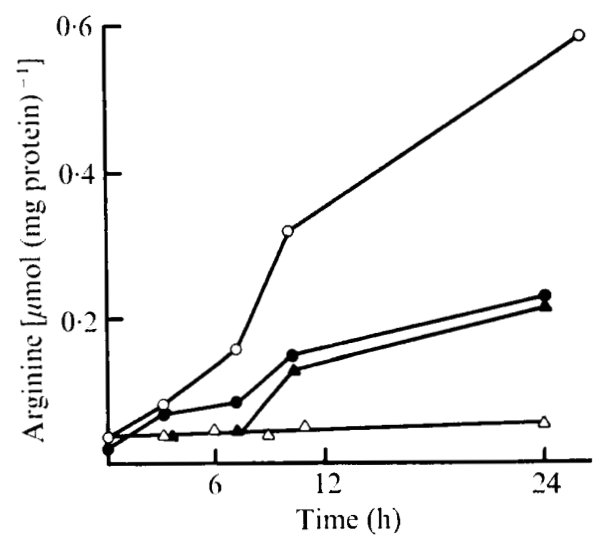

Fig. 2

Fig. I. Accumulation of arginine by conidia of amino acid auxotrophs incubated in MM: 0 , prol-3; 0 , arg-5; $\triangle$, arg-5 prol-3; $\Delta$, arg-6; $\square$, arg-6 prol-3.

Fig. 2. Effect of the carbon source on the accumulation of arginine. Conidia of strain prol-3 were inoculated into: $\bigcirc, \mathrm{MM}$ plus $1.5 \%$ sucrose; $O, \mathrm{MM}$ plus $2 \%$ glycerol; $\triangle, \mathrm{MM}$ alone; $\boldsymbol{\Delta}, \mathbf{M M}$ plus glutamine ( $100 \mu \mathrm{g} \mathrm{ml}^{-1}$ ) as nitrogen source and glycerol as carbon source.

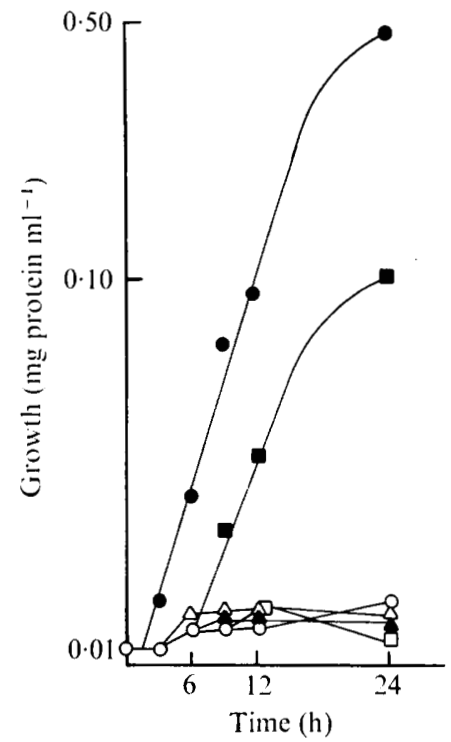

Fig. 3

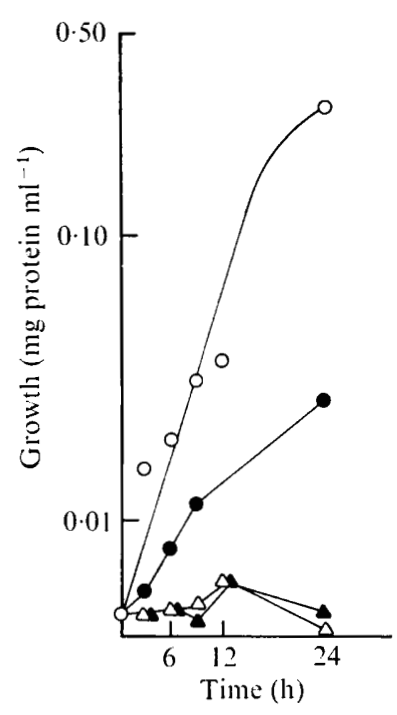

Fig. 4

Fig. 3. Effect of proline deprivation on growth in the presence of arginine or ornithine. Conidia of strain prol-3 were inoculated into $\mathrm{MM}$ at $\circ \mathrm{h}(\mathrm{O})$. The amino acid $\left(100 \mu \mathrm{g} \mathrm{ml}^{-1}\right)$ was added as follows: $O$, arginine at o h; $\triangle, 3 \mathrm{~h} ; \Delta, 6 \mathrm{~h} ; \square, 9 \mathrm{~h} ; \square$, ornithine at $6 \mathrm{~h}$.

Fig. 4. Effect of proline or tryptophan deprivation on growth in the presence of arginine. Conidia of strain prol-3 tryp-2 were inoculated into $\mathrm{MM}$ at $\circ \mathrm{h}$. Indole $\left(20 \mu \mathrm{g} \mathrm{ml}^{-1}\right)$, proline $\left(100 \mu \mathrm{g} \mathrm{ml}^{-1}\right)$ and/or arginine (100 $\mu \mathrm{g} \mathrm{ml}^{-1}$ ) were added as follows: 0 , proline plus indole at $o \mathrm{~h}$; $\bigcirc$, arginine plus indole at $o \mathrm{~h} ; \Delta$, proline at $\mathrm{h}$, removed at $6 \mathrm{~h}$ and indole and arginine then added; $\Delta$, indole at $o \mathrm{~h}$ and arginine at $6 \mathrm{~h}$. 


\section{Table 3. Amino acid analysis of strain prol-3 incubated in $M M$}

The amino acid analysis was performed on the acid-soluble extracts of prol-3 conidia at $\circ \mathrm{h}$ and Io $\mathrm{h}$ after inoculation into MM. Amino acids not shown were below detectable levels. Results are expressed as $\mu \mathrm{mol}$ (mg protein $)^{-1}$.

\begin{tabular}{|c|c|c|c|c|c|}
\hline \multirow[b]{2}{*}{ Amino acid } & \multicolumn{2}{|c|}{$\begin{array}{l}\text { Concn after } \\
\text { incubation for: }\end{array}$} & \multirow[b]{2}{*}{ Amino acid } & \multicolumn{2}{|c|}{$\begin{array}{l}\text { Concn after } \\
\text { incubation for: }\end{array}$} \\
\hline & $\mathrm{oh}$ & IO h & & oh & Io h \\
\hline Aspartic acid & 0.085 & 0.157 & Cysteine & ND & $0.15 I$ \\
\hline Threonine & 0.015 & 0.084 & Methionine & ND & 0.027 \\
\hline Serine & 0.016 & 0.042 & Isoleucine & 0.026 & 0.052 \\
\hline Asparagine & 0.020 & 0.039 & Leucine & 0.011 & 0.009 \\
\hline Glutamic acid & 0.144 & 0.309 & Lysine & 0.200 & 0.120 \\
\hline Glutamine & 0.088 & 0.373 & Histidine & ND & 0.035 \\
\hline Glycine & 0.011 & 0.018 & Arginine & 0.055 & 0.280 \\
\hline Alanine & 0.070 & 0.175 & & & \\
\hline
\end{tabular}

The double auxotroph prol-3 tryp-2 was used to test if the deprivation of amino acids other than proline also prevented the catabolism of arginine. It was found that conidia of this strain deprived of either tryptophan or proline did not catabolize arginine (Fig. 4).

\section{Coordination of the biosynthesis and catabolism of arginine}

Since accumulated arginine was not catabolized, the biosynthesis and catabolism of arginine was studied in the double auxotroph pyr-3a prol-3. Depriving this strain of proline or pyrimidines allowed us to induce the accumulation of arginine. Arginine was accumulated in conidia incubated in MM plus uridine (proline deprivation), but not after incubation with proline (uridine deprivation) (Fig. 5). Proline-deprived conidia did not grow when arginine was added to MM after $3 \mathrm{~h}$, but conidia deprived of uridine grew when uridine and arginine were added (Fig. 6). These results indicate that a coordination mechanism exists between the biosynthesis and the catabolism of arginine, since when arginine was accumulated it was not catabolized, and when it was not accumulated exogenous arginine was catabolized.

Additional evidence of coordination was that conidia of strain prol-3, deprived of proline in the presence of cycloheximide, grew if the inhibitor was removed and arginine added. As shown in Table 2, cycloheximide prevented the accumulation of arginine during deprivation. The conidia were $90 \%$ viable under these conditions.

Coordination was also observed in the presence of glycerol or in the absence of a carbon source. Under these conditions arginine was not accumulated after $6 \mathrm{~h}$ incubation (Fig. 2) and growth occurred when the conidia were transferred to medium containing sucrose and arginine (Fig. 7).

\section{Coordination of the biosynthesis of glutamine and arginine with the catabolism of arginine}

Depriving the conidia of an amino acid in the presence of ammonium, which is normally present in MM, resulted in the accumulation of arginine and in the prevention of its catabolism. Similar results were found using glutamine as a nitrogen source. In the presence of glutamic acid, glutamine and arginine were accumulated at a lower rate during the first $\mathrm{I} 2 \mathrm{~h}$. Only after $24 \mathrm{~h}$ was the intracellular content of these amino acids similar to those found with ammonium (Table 4). The addition of arginine to MM containing glutamic acid as a nitrogen source promoted growth of prol-3 conidia up to $12 \mathrm{~h}$ after amino acid deprivation but not when added after $24 \mathrm{~h}$ (Fig. 8). 


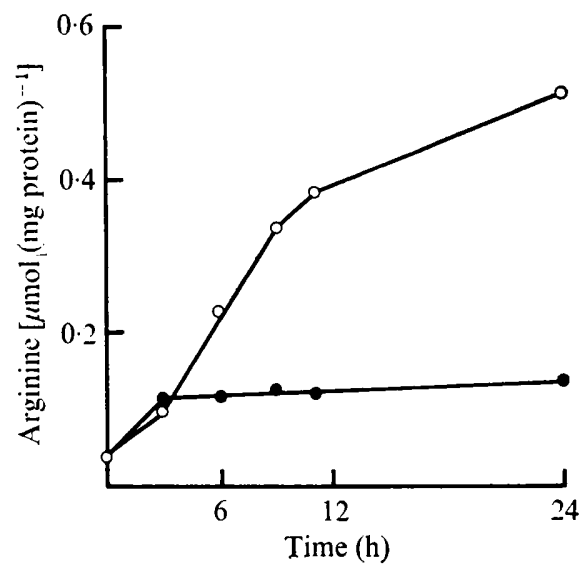

Fig. 5

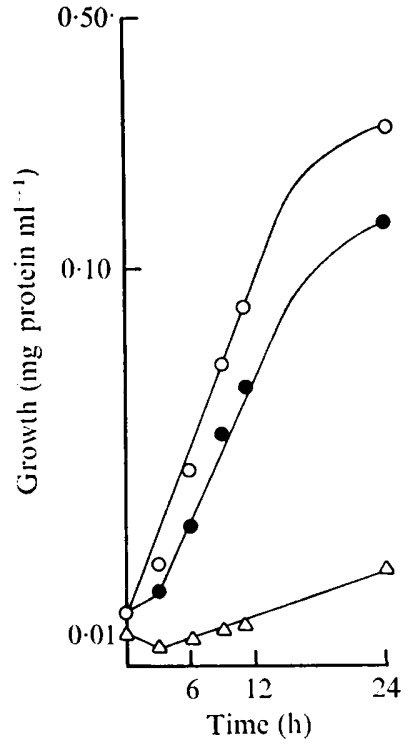

Fig. 6

Fig. 5. Effect of proline or uridine deprivation on the accumulation of arginine. Conidia of strain pyr-3a prol-3 were incubated in MM plus $100 \mu \mathrm{g} \mathrm{ml}^{-1}$ of either uridine $(O)$ or proline $(\bullet)$.

Fig. 6. Effect of proline or uridine deprivation on growth in the presence of arginine. Conidia of strain pyr-3a prol-3 were inoculated into MM at o h and $100 \mu \mathrm{g} \mathrm{ml}^{-1}$ of each supplement was added as follows: $O$, arginine plus uridine at $\mathrm{h}$; $\boldsymbol{O}$, proline at $\mathrm{oh}$, removed at $3 \mathrm{~h}$ and arginine and uridine added; $\Delta$, uridine at $\mathrm{h}$ and arginine added at $3 \mathrm{~h}$.

\section{DISCUSSION}

The accumulation of arginine in conidia deprived of an amino acid is the result of a biosynthetic process dependent on the provision of a carbon source, nitrogen and protein synthesis. The requirement for de novo synthesis of pyrimidines indicates that some synthesis of nucleic acids is also necessary for accumulation.

The accumulation of arginine was initially detected during proline deprivation in the proline auxotroph prol-3. It is surprising that this mutant does not grow in MM but nevertheless accumulates a large arginine pool. Since the addition of ornithine but not of arginine allows growth to occur, we conclude that during amino acid deprivation, accumulated arginine is not hydrolysed by arginase. We have found that glutamine inhibits the growth of strain prol-3 in arginine and prevents the induction of arginase by arginine (Vaca \& Mora, 1977). The inability of amino acid-deprived conidia to catabolize arginine, accumulated through biosynthesis or from the medium, may be explained as a result of the accumulation of glutamine which also occurred during deprivation.

Mycelium of $N$. crassa, deprived of an amino acid, accumulates glutamine and arginine and a substantial amount of this arginine is sequestered, and is unable to induce the arginase even when added to the medium (Mora et al., 1978). Recently, it has been reported that arginine is sequestered in exponentially growing mycelium of $N$. crassa (Weiss, 1973).

When Neurospora is deprived of an amino acid, it does not grow and glutamine is synthesized in excess. Under these conditions arginine neither prevents its own synthesis nor induces its own catabolism. Wiame (197I) has provided evidence and a model for the coordination of the biosynthesis and catabolism of arginine in Saccharomyces cerevisiae. We suggest that during amino acid starvation in Neurospora, glutamine and arginine are accumulated as nitrogen and/or carbon reservoirs. This would imply a link between the biosynthesis of glutamine and the biosynthesis and catabolism of arginine. 


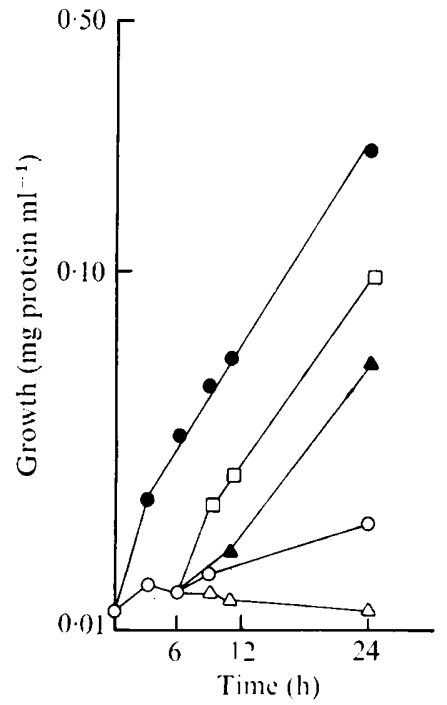

Fig. 7

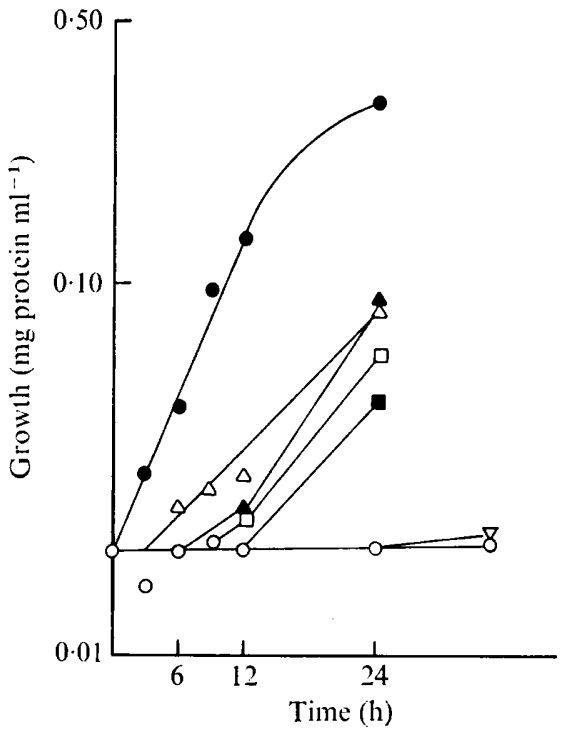

Fig. 8

Fig. 7. Effect of the carbon source on growth. Conidia of strain prol-3 were incubated in: $\bigcirc, \mathrm{MM}$ plus $\mathrm{I} \cdot 5 \%$ sucrose;, $\mathrm{MM}$ plus sucrose plus arginine $\left(100 \mu \mathrm{g} \mathrm{ml}^{-1}\right) ; \triangle, \mathrm{MM}$ plus sucrose with arginine added at $6 \mathrm{~h} ; \Delta, \mathrm{MM}$ plus $2 \%$ glycerol, transferred at $6 \mathrm{~h}$ to $\mathrm{MM}$ plus sucrose plus arginine; $\square, \mathrm{MM}$ alone, transferred at $6 \mathrm{~h}$ to $\mathrm{MM}$ plus sucrose plus arginine.

Fig. 8. Effect of arginine on growth in the presence of glutamic acid after proline deprivation. Conidia of strain prol-3 were incubated in MM (without $\mathrm{NH}_{4} \mathrm{NO}_{3}$ ) plus glutamic acid (5 mM) as nitrogen source plus $\mathrm{I} \cdot 5 \%$ sucrose $(0)$. Arginine $\left(100 \mu \mathrm{g} \mathrm{ml}^{-1}\right)$ was added at: $0,0 \mathrm{~h} ; \Delta, 3 \mathrm{~h}$; $\Delta, 6 \mathrm{~h} ; \square, 9 \mathrm{~h} ; \mathbf{\square}, 12 \mathrm{~h} ; \nabla, 24 \mathrm{~h}$.

Table 4. Accumulation of arginine and glutamine by conidia of strain prol-3 in different nitrogen sources

Conidia were inoculated into MM plus I. $5 \%$ sucrose plus either nitrogen source at $\circ \mathrm{h}$. Concn [ $\mu \mathrm{mol}$ (mg protein) $\left.{ }^{-1}\right]$ of:

$\begin{array}{lccc}\text { Nitrogen source } & \text { Time }(\mathrm{h}) & \text { Arginine } & \text { Glutamine } \\ \mathrm{NH}_{4} \mathrm{NO}_{3}(25 \mathrm{mM}) & 0 & 0.02 & 0.06 \\ & 6 & 0.25 & 0.20 \\ & 12 & 0.46 & 0.37 \\ \text { Glutamate (5 mM) } & 24 & 0.75 & 0.48 \\ & 6 & 0.18 & 0.12 \\ & 12 & 0.17 & 0.13 \\ & 24 & 0.67 & 0.44\end{array}$

The results presented here bear some similarity to those found in mycelium of Neurospora (Carsiotis \& Jones, 1974; Carsiotis et al., 1974) and in S. cerevisiae (Schurch et al., 1974), where a metabolic block in one particular biosynthetic pathway such as arginine, histidine or tryptophan led to a derepression of the enzyme levels in these pathways. In $S$. cerevisiae a similar derepression is observed in leaky mutants of the amino acid pathways mentioned above (Delforge, Messenguy \& Wiame, 1975). The accumulation of amino acids reported here differs in that more than half of the amino nitrogen is accumulated in arginine and glutamine by conidia that are not growing, and a link exists between the catabolism of nitrogen and the synthesis of glutamine and arginine. 
We wish to thank Dr Rafael Palacios for his criticism throughout this work, and Dr Kaethe Willms and Dr Marcella Voght for helping us with the manuscript. We also wish to thank Manuel Cardoso for his help in part of this study. This research was supported in part by CONACYT (Consejo Nacional de Ciencia y Tecnología, México).

\section{REFERENCES}

CARsiotis, M. \& Jones, R. F. (1974). Cross-pathway regulation: tryptophan-mediated control of histidine and arginine biosynthetic enzymes in Neurospora crassa. Journal of Bacteriology II9, 889-892.

Carsiotis, M., Jones, R. F. \& Wesseling, A. C. (1974). Cross-pathway regulation: histidinemediated control of histidine, tryptophan, and arginine biosynthetic enzymes in Neurospora crassa. Journal of Bacteriology 119, 893-898.

Castañeda, M., Martuscelli, J. \& Mora, J. (1967). The catabolism of L-arginine by Neurospora crassa. Biochimica et biophysica acta r4I, 276-282.

Chinard, F. P. (1952). Photometric estimation of proline and ornithine. Journal of Biological Chemistry 199, 9I-95.

DAVIS, R. H. \& MORA, J. (1968). Mutants of Neurospora crass $a$ deficient in ornithine- $\delta$-transaminase. Journal of Bacteriology 96, 383-388.

Davis, R. H., Lawless, M. B. \& Port, L. A. (I970). Arginaseless Neurospora: genetics, physiology and polyamine synthesis. Journal of Bacteriology ro2, 299-305.

Delforge, J., Messenguy, F. \& Waime, J. M. (1975). The regulation of arginine biosynthesis in Saccharomyces cerevisiae. The specificity of arg $\mathbf{R}^{-}$mutations and the general control of amino acid biosynthesis. European Journal of Biochemistry 57, 23 I-239.

Ferguson, A. R. \& Sims, A. P. (1974). The regulation of glutamine metabolism in Candida utilis: the role of glutamine in the control of glutamine synthetase. Journal of General Microbiology 80, I 59-17I.

Lowry, O. H., Rosebrough, N. J., Farr, A. L. \& RaNDALl, R. J. (195I). Protein measurement with the Folin phenol reagent. Journal of Biological Chemistry 193, 265-275.

Mora, J., Salceda, R. \& Sánchez, S. (1972). Regulation of arginase activity by intermediates of the arginine biosynthetic pathway in Neurospora crassa. Journal of Bacteriology 110, 870-877.

Mora, Y., Espín, G., Willms, K. \& Mora, J. (1978). Nitrogen accumulation in mycelium of Neurospora crassa. Journal of General Microbiology 104, 24I-250.
Pall, M. L. (1969). Amino acid transport in Neurospora crassa. I. Properties of two amino acid transport systems. Biochimica et biophysica acta I73, I13-I 27.

Pall, M. L. (1970). Amino acid transport in Neurospora crassa. II. Properties of a basic amino acid transport system. Biochimica et biophysica acta 203, 139-I 49.

Sánchez, S., Martínez, L. \& Mora, J. (1972). Interactions between amino acid transport systems in Neurospora crassa. Journal of Bacteriology I12, 276-284.

Schurch, A., Miozzari, J. \& Hutter, R. (1974). Regulation of tryptophan biosynthesis in Saccharomyces cerevisiae: mode of action of 5-methyl tryptophan sensitive mutants. Journal of Bacteriology 227, I I 3 I-I I 40.

VACA, G. \& MORA, J. (1977). Nitrogen regulation of arginase in Neurospora crassa. Journal of Bacteriology r3I, 7I9-725.

Van Pilsum, J. F., Martin, R. P., Kito, E. \& Hess, J. (I956). Determination of creatine, creatinine, arginine, guanido-acetic acid, guanidine and methyl-guanidine in biological fluids. Journal of Biological Chemistry 222, 225-236.

VOGEL, H. J. (1964). Distribution of lysine pathways among fungi: evolutionary implications. American Naturalist $98,435-446$.

VoGel, H. J. \& BonNeR, D. M. (1954). On the glutamate-proline-ornithine inter-relation in Neurospora crassa. Proceedings of the National Academy of Sciences of the United States of America 40, 688-694.

WEISS, R. L. (I973). Intracellular localization of ornithine and arginine pools in Neurospora. Journal of Biological Chemistry 248, 5409-54I 3.

WIAME, J. M. (I97I). The regulation of arginine metabolism in Saccharomyces cerevisiae: exclusion mechanism. In Current Topics in Cellular Regulation, vol. 4, pp. I-38. Edited by B. L. Horecker and E. R. Stadtman. New York: Academic Press.

Yemm, E. W. \& Cocking, E. C. (1955). The determination of amino acids with ninhydrin. Analyst 80, 209-2 I4. 